\title{
El estigma del nombre propio: un acercamiento literario a la onomástica femenina de la alteridad
}

\author{
YASMina ROMERO MORALES \\ Universidad de La Laguna
}

Resumen: El objetivo principal de este artículo es llamar la atención sobre la onomástica literaria como mecanismo de alteridad. Las próximas páginas se proponen acercarse a los nombres propios más habituales que reciben los personajes femeninos marroquíes en la narrativa española de ficción escrita por mujeres durante el siglo XX. Se parte de la hipótesis de que el nombre propio atribuido a la otredad marroquí es mucho más que un signo lingüístico, funciona como un marcador identificativo del personaje dentro de una comunidad concreta y responde a una estrategia propia del principio de alteridad que permite diferenciar al «nosotros/as» del «ellos/as».

Palabras clave: Onomástica, alteridad, narrativa española, mujeres escritoras, mujeres marroquíes.

The stigma of the proper name: a literary approach to the feminine onomastic of otherness

Abstract: The main objective of this article is to pay attention to the literary onomastics as a mechanism of otherness. The following pages propose to approach the most common names that Moroccan female characters receive in the Spanish fiction narrative written by women during the 20th century. It starts from the hypothesis that the proper name attributed to Moroccan otherness is much more than a linguistic sign, works as a marker identifying the character within a particular community and responds to its own strategy of the principle of otherness that allows to distinguish between us and them.

Keywords: Onomastics, Otherness, Spanish Narrative, Women Writers, Moroccan Women 


\section{INTRODUCCIÓN}

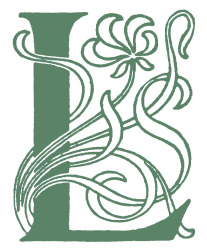

a narrativa española de tema marroquí es característicamente copiosa en el conjunto general de la literatura española, sobre todo, aquella que se publica en los años de mayor relación histórica entre España y Marruecos y que devuelve más de doscientos títulos, sólo de ficción, publicados desde el siglo XIX hasta la actualidad. Sin embargo, entre los nombres de los autores más conocidos - Ramón J. Sender, José Díaz Fernández o Arturo Barea - es poco frecuente encontrar nombres femeninos, al menos, no más allá de conocidas escritoras como Carmen de Burgos. Para este, y otros trabajos de investigación similares, he escogido como corpus únicamente los textos de mujeres escritoras que durante el siglo XX decidieron relatar a Marruecos, un total de veintidós autoras ${ }^{1}$, a las que de alguna manera he querido visibilizar como denuncia a la institución literaria que no sólo se organiza clasistamente sino, también, de forma sexista. Lo cierto es que, además de rescatarlas a ellas y a sus sesenta y dos textos ${ }^{2}$, este fecundo material para la investigación, nunca aunado antes, me ha permitido analizar de forma pormenorizada la construcción de la identidad de la otredad femenina marroquí en esos mismos textos.

Asegura Milagros Ezquerro que «El personaje novelesco es una construcción verbal destinada, generalmente, a representar a una persona. El personaje se compone de todo lo que el texto dice de él» (Ezquerro, 1990: 13). Y lo que estos textos dicen de la «otra» marroquí, desafortunadamente, colabora en la perpetuación de tópicos y estereotipos interesados que en este trabajo he pretendido desmitificar y que predisponen a la sociedad hacia la totalidad de mujeres de contextos árabe-islámicos. Una predisposición que se ve propiciada en el escenario actual por el fecundo caldo de cultivo que traen aparejados discursos populistas de carácter islamófobo.

\footnotetext{
1 Carmen Martel, Concha López Sarasúa, Encarna Cabello, Marisa Villardefrancos, Regina Flavio, Concha Linares-Becerra, Mari Paz Estévez de Castro, Cristina Fernández Cubas, Carmen de Burgos, María Charles, Carmen Martín de la Escalera, María Teresa de Jadraque, María Viñuelas, Blanca Ibáñez Blanco, Josefina María Rívas, Rosa de Aramburu, María Adela Durango, Margarita Astray Reguera, Rosa María Aranda, Julia María Abellanosa, Carmen Nonell y Dora Bacaicoa.

2 Las novelas y relatos que conforman las fuentes primarias podrán ser consultadas en las referencias bibliográficas que se encuentran al final de este trabajo.
} 
El método utilizado para la elaboración de este trabajo, además del propiamente filológico y literario, responde al de una serie de teorías diferentes pero que están en conexión por tener en común «intentar demostrar que lo que damos por seguro como de sentido común es, de hecho, una construcción histórica» (Culler, 2014: 15). Estas son: los estudios culturales que privilegian una lectura ideológica de la cultura, la perspectiva de género más antiesencialista inspirada en autoras como Judith Butler o Nancy Fraser y las teorías postcoloniales. Dentro de éstas últimas, principalmente la obra legada por la que ha sido considerada la «Santísima Trinidad» del análisis del discurso colonial: Edward W. Said, Homi K. Bhabha y Gayatry Spivak.

De acuerdo con esto y teniendo como foco de interés la identidad femenina marroquí construida en el conjunto de textos analizados, me percaté de la importancia que tenían en sí mismos los nombres propios que se le atribuían. El nombre propio que se le atribuye a la «otra» marroquí funciona como un marcador identificativo de ese personaje dentro de una comunidad concreta, incluso de una comunidad literaria, y llamarla por su propio nombre significa reconocerla como individuo y situarla, por decirlo como Judith Butler, «dentro del discurso» (2002: 181). Visto de esta manera, despojar a un personaje de su nombre propio conllevaría dejarlo relegado al espacio de los ignorados, de los olvidados, de los desconocidos. Negar su existencia y su identidad individual. Por todo ello, lo más frecuente es que en esta narrativa española de tema marroquí, en sí misma una narrativa de colonias ${ }^{3}$, se opte por no llamar a los personajes femeninos autóctonos con nombres propios, sino acudir al genérico moras ${ }^{4}$ como un modo de subrayar su condición de objetos literarios y su devenir normativo como otredad absoluta. Algo muy usual también en los medios de comunicación actuales que, para referirse a la mujer migrante de contextos árabe-islámicos, optan por sustantivaciones

\footnotetext{
3 Entiendo por narrativa de colonias la definición ofrecida por Carrasco González, como «Esa manera de narrar sobre países alejados sin pertenecer al pueblo natural de ellos y con un sentimiento o mentalidad mayor o menor, de alteridad» (2009: 9). A lo que, además, debemos añadir la factual relación colonial que llevara España con Marruecos durante gran parte del siglo XX, recordemos que la zona norte del país magrebí fue Protectorado Español desde 1912 hasta 1956.

4 De aquí en adelante se utilizará el término moro/a como denotación léxica, ya que es el término más usado por las autoras estudiadas para designar a la población autóctona. En ningún momento está utilizado de manera irrespetuosa o peyorativa como sí sucede en la actualidad de los discursos cotidianos. Luz Gómez García en la entrada moro de su Diccionario de islam e islamismo (2009) recoge esta ambigüedad del término al hacer referencia a la convivencia en la misma palabra de estas dos aproximaciones, una despectiva y una más amable como en la expresión «bajarse al moro».
} 
genéricas que no reconocen ningún tipo de identidad individual. Se describen seres abstractos, descontextualizados y, así, no sólo es muy difícil despertar la empatía, sino que se la encaja en una categoría social subordinada como un modo de producir y regular identidades colectivas.

En el mejor de los casos, las ficciones analizadas adoptan los nombres propios locales más repetidos - como María o Carmen en la cultura española para definir a la totalidad de las marroquíes en una despersonalización que sirve al ojo colonizador para simplificar. Justo es a esos nombres propios, los más usuales y de mayor aparición en la narrativa española de ficción escrita por mujeres durante el siglo XX, a los que haré alusión en las próximas páginas, un acercamiento que pone en relación la onomástica y la alteridad y que no ha visto reflejada en la bibliografía específica más que en algunos trabajos puntuales y nunca de narrativa española de temática marroquí 5 .

Ese es el objetivo principal de esta contribución, llamar la atención sobre la onomástica literaria. Y, puntualizo que sólo literaria, porque la onomástica es una disciplina de orientación fundamentalmente lingüística, un área que se aleja del ámbito literario que ocupa al presente trabajo. Conviene subrayar, por tanto, que mi aproximación no aspira a ser sociológica, ni histórica, ni antropológica sino, como digo, enteramente literaria. En ningún caso he pretendido aumentar con otra aportación más, la larga nómina de textos dedicados al estudio de la situación real de las mujeres marroquíes o de cualquier otro contexto árabe-islámico. Sobre todo, porque los textos analizados no nos dirían, aunque así lo buscáramos, cómo eran realmente las mujeres marroquíes habida cuenta que, escritos por mujeres españolas, nos revelan información de contenido ideológico, pero no sobre las mujeres marroquíes, sino sobre las propias autoras, sobre cómo percibían, suponían y pensaban a la «otra» marroquí que imaginaban.

\section{EL NOMBRE PROPIO COMO ESPACIO DE IDENTIDAD}

La narrativa española de tema marroquí demuestra con múltiples ejemplos que el nombre propio es mucho más que un signo lingüístico. Por ejemplo,

5 Véase IONESCU, Christian (1993), «Onomástica literaria: dominio interdisciplinar» en Butlletí de la Societat d'Onomàstica, págs. 305-315. 
cuando explica lo sucedido con los emigrantes españoles afincados en Marruecos durante el pasado siglo XX. Éstos decidieron adaptar sus nombres y apellidos a la fonética del francés, afrancesarlos para con ello aspirar a una mejor consideración social de su entorno. Se desidentificaron onomásticamente para rebautizarse, querían simular ser franceses -una cultura que demostró ser superior a España en lo que a ejercer su dominio colonial en Marruecos se refiere- $\mathrm{y}$, como advierte Abrighach, también para «camuflar [su] sentimiento de infravaloración» (2009: 185). Algunas de las ficciones estudiadas le dan bastante espacio a este hecho, sobre todo, aquellas que salpican sus tramas con lo que consideran un tipo concreto de nombre intercultural:

Roxette, la chica de los Fernández, se acercaba. En realidad se llamaba María Rosa pero había acostumbrado a los amigos a que le dijeran Roxette, suena más dulce, más francés, opinaba (López Sarasúa, 2000: 20).

El apellido lo habían adaptado también, como otros muchos españoles, a la pronunciación francesa: Rodríguez, Fernández, López. La zeta, precedida por la vocal bien acentuada, los acercaba al mundo francófono al que casi todos habrían querido pertenecer (López Sarasúa, 2000: 20).

Había nacido en Orán ya iba para cincuenta y tres años; su nombre de pila era Rosario pero, por el trabajo que ejercía y el trato habitual con los residentes francófonos, la conocían solamente por el apellido. De cualquier manera lo preferí; no encontraba razón alguna para que sus padres la hubiesen bautizado con el nombre de Rosario (López Sarasúa, 2000: 207).

Como vemos, estamos ante una narrativa que identifica al nombre propio como un espacio de identidad por lo que los nombres asignados a la «otra» marroquí que imaginan para sus tramas también son parte de ese intento de catalogación social. Los nombres caracterizan y contienen al sujeto colonial tanto colonizador como colonizado-, incluso porque es más fácil seguir así el desarrollo de la historia. Los personajes de esta narrativa, destinada al gran público, tienen nombres cotidianos, para que el lector se sienta identificado y crea que puede sucederle a él mismo, a un compañero de trabajo o a un vecino. En esta narrativa los nombres de las moras deben ser de consumo rápido y de rápida asociación. El nombre propio se convierte, entonces, en elemento esencial en la construcción del personaje y contribuye de manera eficaz a la comunicación entre autora y público lector, ya que el carácter supuestamente 
típico fomenta la posibilidad de reconocimiento. Por un nombre de resonancias árabes, inferimos en esta narrativa que la «otra» marroquí es mora. El nombre ha descubierto su identidad.

- ¿Cómo te llamas?

- Rahama, ¿Te gusta?

- No sé. Sería lo único que me gustase de ti (Aranda, 1945: 63-4).

Este breve intercambio de frases tiene lugar en la novela Tebib (1945). El protagonista es el español Alfonso y el manifiesto rechazo lo siente hacia una joven prostituta de la que por su nombre sabe ya que es mora. Una muestra más, la hallamos en el relato «Naima», incluido en el volumen A vuelo de pájaro sobre Marruecos (1988) donde la narradora describe a una campesina que viaja en tren hacia Tánger y de la que admite que «no lleg[ó] a conocer su verdadero nombre» (López Sarasúa, 1988: 140). Sin embargo, decidió llamarla Naima, un nombre marroquí. La protagonista de la historia, posicionada en el poder discursivo, interpretó su cuerpo a golpe de vista como marroquí y el nombre debía ir en consonancia para garantizar su identidad coherente en el discurso colonial. Mismo mecanismo encontrado en La llamada del almuédano (1990) donde la protagonista, una española afincada en Marruecos que decide volver a España, sin quererlo, alterna su nombre con el de Laila: «No te irás, no permitiremos que te vayas. Te ocultaremos en lugar seguro, donde puedas embriagarte de aleyas; no temas, Laila, el tiempo es nuestro y este país te pertenece por los siglos de los siglos...» (López Sarasúa, 2000: 254).

De alguna manera este recurso disipa la condición de forastera de la protagonista en Marruecos, a la vez que contribuye a la empatía hacia el hábitat que la rodeaba y que el público lector dedujese su inherente sentimiento de arraigo. El personaje se siente tan de Marruecos que es ya mora y, por tanto, su nombre debe adaptarse a esa nueva realidad.

En la novela Cita en el paraíso (1941) de Concha Linares Becerra hallamos otro ejemplo especialmente interesante al respecto de los nombres propios. Esta historia narra el encuentro de una serie de desconocidos - ninguno marroquí - en una casa en la sierra de Tetuán, un lugar llamado en árabe $P a-$ raíso donde - a modo de la novela Diez negritos de Agatha Christie - han 
sido invitados por un anfitrión que se oculta entre los propios huéspedes. Allí, las reglas establecidas por el propietario imponían el anonimato y, para ello se les pidió que adoptaran los seudónimos que quisieran durante su estancia: aparece entonces un Don Nadie, una Meiga, un Emancipado, un Látigo pero también una "gordinflona señora constelada en alhajas» (Linares Becerra, 1962: 104) que decide llamarse Zoraida, complemento indispensable para su cambio de identidad, que ahora apunta a la prototípica mujer de contextos árabe-islámicos: «encerrada en sus habitaciones» y pasando interminables horas «vestida de sultana extendida en un diván» (Linares Becerra, 1962: 108). La adaptación del nombre se efectúa acorde con el proceso de inmersión cultural que iba a llevar a cabo, esto es, las actitudes que le suponía propias a la «otra» marroquí y que ella haría propias durante las dos semanas que pasaría en Marruecos.

La elección de un nombre árabe es un sello identificativo para convertirse - aunque fuera de forma simulada - en mora. Algo que también consideran algunas conversiones religiosas, entre ellas el islam, que proponen un cambio de nombre a sus nuevos fieles. Vistas así las cosas, veamos cuáles son los nombres femeninos más frecuentes hallados en la narrativa de colonias analizada.

\section{LA IMPORTANCIA DE LLAMARSE FÁTIMA}

La narrativa de tema marroquí propone algunos nombres propios atribuidos a la otredad femenina local. En los sesenta y dos textos que conforman el corpus documental he podido encontrar alrededor de doscientos cincuenta personajes femeninos marroquíes con nombre propio de los cuales señalaré los cuatro que más prevalecen, ordenados todos ellos por orden de mayor a menor frecuencia ${ }^{6}$. Estos nombres asignados a la «otra» marroquí cuando

\footnotetext{
6 A modo de curiosidad refiero el resto de inventario onomástico por orden alfabético y con la grafía encontrada, que no responde a ningún sistema de transcripción fonética internacional sino a la reproducción intuitiva de las autoras. Este hecho arbitrario explica la incongruente repetición, en ocasiones, de los mismos nombres con pequeñas y ambivalentes variantes: Aauch, Ahda, Ainalma, Ambar, Amina, Arbuissa, Arjimo, Auisa, Axixa, Axuxa, Ayuba, Bachía, Bechira, Bushra, Camla, Dunia, Erhimo, Erjimo, Erquía, Farida, Fattuch, Fettom, Gina, Hadduya, Hadush, Haduxa, Hafida, Halima, Handuya, Hanina, Hind, Iasmina, Inmra, Jadduch, Jadduxx, Jadduya, Jadiya, Jaira, Kensa, Laila, Lala, Lasmía, Latifa, Lobna, Luazna, Lubana, Luiza, Malica, Malika, Melikah, Menana, Menuch, Mequeltum, Meriem, Mimuni, Mina, Mnama, Muna, Nadia, Naima, Naryis, Nawar, Nayat, Nefisa, Neima, Nerlia, Neyma, Nkulchum, Nocija, Nur, Quinza, Raahma, Rabiah, Racucha, Rahama, Rahma, Rajma, Ratiba, Redia, Roahma, Sadia, Saida, Saquina, Sheila, Sineb, Soad, Sobeida, Suad, Táhera, Tamo, Tazza, Traimas, Turía, Uarda, Uia, Xodia,
} 
es mora no están atribuidos al azar ${ }^{7}$, conllevan una identidad social adherida que mantiene las categorías fronterizas que distinguen sin dificultad el «nosotras» del «ellas». Ya que, como señalo, los nombres son en sí mismos un soporte de información ${ }^{8}$. Y más en escenarios coloniales, aunque sean narrativos, porque en ellos la impronta de la jerarquía social es, junto con el control visual, fundamental. No obstante, a pesar de las breves notas que agrego a cada uno de ellos, más allá de avisar al público lector que la «otra» marroquí es mora - «el velo del nombre» lo llamó Manuela Marín (2015: 185) -, no cumplen otra función connotativa, como he advertido. Designan sin identificar. No hay diferenciación entre unos nombres propios y otros, no se diferencian las portadoras en sus comportamientos, ni en sus funciones, ni en sus cualidades o sus defectos:

Fátima: El nombre de Fátima, con todas las variedades dialectales existentes en el propio árabe marroquí y, también, con todas las consiguientes variantes de adaptación a la lengua castellana - Fama, Fattoma o Fatma - es el que más aparece para denominar a la «otra» marroquí en esta narrativa cuando se quiere indicar que es mora. De la misma manera lo reconocen algunas de nuestras autoras que, en cuanto a nombres, «Fátima es la costumbre» (Aramburu, 1937: 18). En Ojos largos (1937) el personaje de «Fátima ha subido a la terraza. Fátima - la esposa de Mohamed el Diuri, porque Fátimas hay mil en Larache [...]» (Aramburu, 1937: 30). En efecto, Fátimas hay muchas como Marías hay muchas en España, hasta el punto de utilizar ese mismo nombre - junto al de Yasmina - como sustantivación genérica para designar al resto de moras en general. Dice un fragmento de una de las novelas refiriéndose a las mujeres:

Yamaa, Yamila, Yamina, Yasmina, Yasminah, Zahira, Zama, Zauzia, Zaynab, Zineb, Zobaida, Zobeida, Zoraida y Zubida.

7 Hago esta apreciación porque la «otra» marroquí puede no ser mora en todos los casos y esta narrativa lo tiene en cuenta como en el caso de los personajes judíos. Sin embargo, su aparición es infinitamente inferior por lo que el inventario de nombres propios femeninos recogidos también es mucho más reducido. Entre los más habituales Ruth, Micol, Raquel, Amor, Alma y, sobre todo, Esther. Este último es el nombre más usual cuando las autoras quieren subrayar que la «otra» marroquí es judía. Preferir nombres propios del Antiguo Testamento - como ya han advertido algunas investigadoras (Martín-Márquez, 2011: 29) - ha sido una práctica corriente en la literatura española para hacer entender la supuesta adhesión judía del personaje.

8 Ese es el motivo por el que muchas personas, para salvar su vida, han decidido cambiarlos. En época nazi, por ejemplo, fue una verdadera obsesión la persecución de los nombres judíos.

9 Algunos investigadores han criticado «cómo los autores e impresores españoles suelen maltratar las palabras extranjeras» (Kunz, 2002: 179) 
Sentábanse a estilo árabe en los largos divanes que bordeaban las estancias recargadas de cojines y tapices, alfombras y objetos caros, y en las que resaltaban, por lo repetidos, relojes de nuestros comedores de la clase obrera-, y al lado y encontraste, maravillosos espejos sin utilidad práctica, pues que colgados cerca del techo, sólo un gigante - alguna gigantesca Fátima o Yasmina - alcanzaría a mirarse (Linares Becerra, 1971: 302-3) [La cursiva es mía].

Este uso metonímico como estereotipo colectivo ha sido común en contextos coloniales, no sólo en Marruecos. Autores como Frantz Fanon han denunciado que fue frecuente también en Argelia (1976: 34), de ello resulta que se localice en multitud de casos este mecanismo despersonalizante en las ficciones analizadas. Sirva de muestra La llamada del almuédano (1990) de Concha López Sarasúa donde se denomina «la Fátima» o «la fatma» a la mora que tenían como criada doméstica unos españoles - es el «nombrar inapropiadamente» al que ha hecho referencia Homi K. Bhabha (2011: 270) ${ }^{10}$ - dado que, en realidad, se llamaba Muna (López Sarasúa, 2000: 76). Los casos se multiplican, valgan dos más de justificación, la asistenta de nombre Malika a la que llaman «la fatma» (López Sarasúa, 2000: 190) o la forma de hablar displicente, de cualquier vecino, que se refiere a la asistente doméstica de la casa de al lado como «la fatma de la vecina» (López Sarasúa, 2000: 216).

A la literatura le ha gustado el nombre de Fátima para sus personajes femeninos de pretendido origen árabe-islámico, imposible no traer a colación a la esposa de Barba Azul, ya sabemos, ese personaje de larga barba y turbante que creara Charles Perrault. En la actualidad, y ya no estrictamente en el ámbito literario, es un recurso habitual el utilizar este nombre para aludir al origen árabe-islámico de su portadora. Lo vemos en la película Fátima (2015) de Philippe Faucon que relata la historia de una musulmana inmigrante de origen árabe que es madre de dos hijas. También en la protagonista femenina de origen marroquí de la serie española El príncipe (2014-16) y que, como decidió repetir la imagen estereotipada de mujer musulmana sumisa, sin ob-

\footnotetext{
10 Señala Bhabha que una de las acusaciones fundamentalistas ha ido justamente en esta línea. No tan relacionadas con la mala interpretación, por ejemplo, del Corán, sino con la ofensa que conlleva el desplazamiento de nombres propios sagrados a espacios profanos. El ejemplo que recoge es llamar generalizadamente a las mujeres en situación de prostitución con el nombre de las esposas del profeta Mahoma. Algo que no aparece reflejado en la narrativa analizada, pero que el sociólogo Josep Mateo Dieste señala que era común en el Marruecos colonial, que se denominara «Fátimas» a las prostitutas marroquíes de la época (2005: 156).
} 
jetivos, ni personalidad y oprimida tanto por su religión como por los hombres de su comunidad, encontró rápida respuesta en las redes sociales con reportajes como el de "Así somos las Fátimas reales»" ${ }^{11}$.

Aixa: Nombre árabe por definición ya que así se llamó una de las esposas de Mahoma, significa 'la viviente' o 'la que vive'. Es el segundo que más irrumpe en esta narrativa y, en la actualidad, sigue siendo uno de los nombres de niña más populares en el mundo islámico sunní12. En los textos aparece con distintas grafías como Aicha, Aisha o Aaicha. En la novela de Mari Paz Estévez, El convoy de la muerte (1954), cuando la protagonista, una joven francesa, quiere hacerse pasar por marroquí, es el nombre que escoge. Además, este nombre tiene su propia impronta en el orientalismo español ya que hace referencia al tema granadino. Aixa fue una reina de Granada que opuso especial resistencia a los Reyes Católicos. También fue la madre de Boabdil, aquél al que le dijo la mítica frase de «llora como una mujer, lo que no supiste defender como un hombre» cuando su hijo volvió la vista atrás para contemplar Granada por última vez. En efecto, a la literatura en general, no sólo la de tema marroquí, le ha gustado denominar Aixa al personaje de origen árabe-islámico, recordemos, por poner otro ejemplo, que así se llamaba la doncella mora enamorada del protagonista en el Guerrero del Antifaz.

Zohra: Este es el tercer nombre más habitual para denominar a la «otra» marroquí cuando es mora, probablemente porque era el segundo nombre de la hija del profeta Mahoma, el primero, Fátima. Cabe señalar que al igual que los casos anteriores, en la narrativa analizada este nombre puede tener distintas grafías: Sojora, Zahara, Zóhora o Zahra. Unas grafías que en unos casos refiere a variantes de la propia lengua dialectal marroquí y, en otros casos, de las diferentes adaptaciones al castellano. Aparece así Zohra, la protagonista de «Tras los eucaliptos» un cuento de Concha López Sarasúa incluido en $A$ vuelo de pájaro sobre Marruecos (1988), donde se asegura que Zohra tiene un pacto con el diablo. No debe sorprendernos, recordemos que en esta narrativa la «otredad» marroquí representa a los malos de la historia, lo que Vladimir Propp en La morfología del cuento (1928) denominó «agresor del protagonista» (2014: 40) y que vienen a «provocar una desgracia, hacer el mal, causar un prejui-

11 Acceso el 28 de diciembre de 2016. http://www.pikaramagazine.com/2016/04/asi-somos-las-fatimas-reales/

12 Y hago esta salvedad porque, entre los shiíes, es usado como un insulto. 
cio» (2014: 41). La eterna lucha del Bien y el Mal de un mundo simplificado donde se identifica al lector con el héroe - el español-, siempre más atractivo en su bondad y justicia, que su antagonista, el moro o, en este caso, la mora.

Un ejemplo más, entre tantos que asoman en esta narrativa, de «otra» marroquí denominada Zohra, es la que aparece en El sol nace de madrugada (1953), en este caso, asociada con el mal que apareja convertirse en tentación para los hombres occidentales, incapaces de resistirse a la atracción que supone la «otra» marroquí poseedora del don de la eterna juventud ${ }^{13}$.

-¿Qué edad crees tú que tendrá Zahara?

$[\ldots]$

- Yo qué sé. Catorce, quince, dieciséis años...

- ¡Qué barbaridad! Son infernales estas chiquillas.

(Villardefrancos, 1953: 15)

Amina: Cuarto nombre más acostumbrado, significa segura, 'que siente seguridad'. Las diferentes variantes dialectales hacen que, en ocasiones, se refleje en los textos también su acortamiento Mina, pero propuesto como nombre completo. Amina, o Mina por tanto, es frecuente en esta narrativa de tema marroquí, principalmente por su vinculación religiosa dado que era el nombre de la madre del profeta Mahoma. Veamos uno de los ejemplos de «otra» marroquí con este nombre, se dice, «Amina envuelta en la yilaba, con el capuchón calado hasta los ojos, se moría de cansancio» (Bacaicoa, 1955: 37).

Este nombre se sigue utilizando en la actualidad, desde soportes dirigidos a públicos occidentales, para representar a la otredad femenina cuando es musulmana. Por ejemplo, sucedió así en la taquillera película El niño (2014) dirigida por Daniel Monzón, donde el personaje marroquí del que se enamora el joven protagonista español se llama Amina. O en el recién publicado libro Amina's voice (2017), de Hena Khan, donde se narran las vicisitudes de una adolescente musulmana paquistaní que vive en Estados unidos y que se siente entre medio de dos culturas.

\footnotetext{
13 Algunas investigadoras como Fátima Mernissi han denunciado que este deleite por la belleza prepuberal de las mujeres es de factura más occidental que oriental. El filósofo Richard Rorty, a su vez, ha señalado que la infantilización es una de las formas más usuales de la deshumanización (2000: 221).
} 


\section{A MODO DE CONCLUSIÓN}

La información onomástica pues, de este conjunto de textos literarios, responde a una estrategia propia del principio de alteridad que permite diferenciar al «nosotras» del «ellas» y que, en ningún caso, connota propiedad individual alguna de sus referentes como sí sucede en otras muchas narrativas donde los nombres propios comportan significados semánticos, semióticos, simbólicos y hasta añaden matices que enriquecen lo textos. En esta narrativa española de tema marroquí los personajes locales llevan nombres árabes o de resonancias exóticas o arabizantes, si se quiere especificar que son moros y usan nombres hebreos o de supuesto origen hebreo, si se dice de ellos que son judíos. Esta es la razón por la que no abundan en las fuentes los nombres imaginarios, sino de pretendido origen árabe o hebreo, puesto que funcionan a modo de meras «etiquetas» de identificación.

En efecto, este es un estudio de estereotipos literarios sobre la «otra» marroquí y mi acercamiento ha sido literario pero puede ser extrapolado a la cotidianidad actual en la medida que son los mismos discursos degradantes que encierran al «otro» islámico en su otredad subordinada y que pueden constatarse en las redes sociales, en el discurso institucional de partidos políticos ${ }^{14} \mathrm{y} / \mathrm{o}$ organizaciones, en las aulas donde hay alumnado musulmán o, incluso, derivado de la crisis humanitaria y la posibilidad de llegada de refugiados. Corren tiempos de moda para algunos populismos que patrocinan el rechazo y la hostilidad hacia el islam y hacia los y las musulmanas, recoge la Plataforma Ciudadana contra la Islamofobia en su último informe, que esta conducta de discriminación ha crecido en España un 567,35\% con respecto al año anterior (2016: 7).

Es pertinente preguntarnos entonces si ¿es islamófobo el uso repetido de determinados nombres propios para personajes de supuesto origen árabe-islámico en las creaciones occidentales? En mi opinión sí, dado que, en literatura, por ejemplo, el lector identifica mediante el nombre del personaje la imagen mental que el autor o autora ha querido transmitirle y que, en la mayoría de los casos, refleja ese imaginario compartido y heredado sobre

14 Pondré como desafortunado ejemplo las declaraciones del líder de Convergencia i Unió Josep Antoni Duran i Lleida durante la campaña de las elecciones al Parlamento catalán de 2011: «Estoy preocupado porque en Cataluña nacen más Mohamed que Jordi o José» (Libertad Digital, 2/11/2011) o «Hay muchos Mohameds que no se integran en el país» (Los Desayunos de TVE, 16/11/2011). 
la otredad árabe-islámica cargada de estereotipos, clichés y prejuicios. Pero también sucede en otros soportes además del literario como el cine o la televisión, como se ha ido convenientemente señalando y que, en ningún caso, permiten conocer la individualidad de las personas que los portan - cuando es verdad que los portan - sino que abunda en una masa homogénea que impide la subjetividad individual a la que todos y todas tenemos derecho como personas. No quiero dejar de señalar las preguntas xenófobas de un examen de un cuestionario de evaluación de una asignatura de derecho penal del máster de acceso a la abogacía de la Universitat Oberta de Catalunya (UOC). En dos de las diez preguntas incluidas en el test aparecen los nombres de Mohamed y Nassia Gabul como personas detenidas por vender droga y artículos pirateados, respectivamente. Situaciones muy distintas a las que se enfrentan nombres ficticios más tradicionales en otras dos preguntas del cuestionario: Alberto muere tras ser víctima de una puñalada en una discoteca, mientras que Braulio denuncia a Jordi por haberle insultado mientras salía de su casa ${ }^{15}$.

Definitivamente, la atribución de nombres de supuesto origen árabe-islámico en las creaciones occidentales no suele ser casual ni inocente por lo que este trabajo, con su acercamiento literario a la onomástica femenina de la alteridad en la narrativa española de tema marroquí, ha querido poner al descubierto el estigma que supone y la islamofobia que en la mayoría de los casos suele conllevar, a veces subrayada por una «islamofobia de género» donde se subordina a la «otra» marroquí no sólo por ser de origen árabe-islámico sino, también, por ser mujer. La única posibilidad de subversión, pues, considero que está en la denuncia de estos mecanismos de opresión y desde todos los ámbitos, también, desde la literatura.

\section{REFERENCIAS BIBLIOGRÁFICAS}

Abellanosa, Julia María (1944), Y llegó el plenilunio, Madrid, Gráficas Reunidas.

AвRIGHACH, Mohamed (2009), Superando orillas. Lectura intercultural de la narrativa de Concha López Sarasúa, Rabat, El Maarif Al Jadida.

15 Eldiario.es 15/06/2016. Acceso el 28 de diciembre de 2016 http:/ / www.eldiario.es / catalunya/educacion/Alberto-apunalan-Mohamed-preguntas-UOC_0_526697714.html 
Aramburu, Rosa de (1937), Ojos largos, Madrid, Editorial Española. La Novela Nueva $n^{\circ} 2$.

Aranda, Rosa María (1945), Tebib, Zaragoza, Artes Gráficas E. Bermejo Casañal.

Astray Reguera, Margarita (1925), «Pasión de moro» en Los contemporáneos, Madrid, $n^{\circ} 879$.

BACAICOA, Dora (1955), Zohora la negra y otros cuentos, Tetuán, Colección Manantial.

Bнавна, Hoмi K (2011), El lugar de la cultura, Buenos Aires, Manantial.

- (2013), Nuevas minorías, nuevos derechos. Notas sobre cosmopolitismos vernáculos. Siglo XXI Editores, Buenos Aires.

Burgos, Carmen de (1989), «En la guerra», en Concepción Núñez Rey (ed.). La flor de la playa y otras novelas cortas, Madrid, Castalia, págs. 163-218.

ButLER, Judith (2002), Cuerpos que importan. Sobre los limites materiales y discursivos del «sexo», Buenos Aires, Paidós,

CABello, Encarna (1995), La cazadora, Melilla, Textos Mediterráneos.

- (1999), El cenicero, Granada, Universidad de Granada.

- (2000), Alizmur, Barcelona, Meteora.

CArrasco González, Antonio (2009): Historia de la novela colonial hispanoafricana, Madrid, Sial.

Charles, María (1993), Etxezarra, Barcelona, Editorial Anagrama.

Culler, Jonathan (2014), Breve introducción a la teoría literaria, Madrid, Austral.

Durango, María Adela (1943), Ojos verdes, Madrid, Editorial Pueyo.

Estévez de CAstro, María Paz (1954), El convoy de la muerte, Madrid, Editorial Pueyo. 
EzQuerro, Milagros (1990), «La paradoja del personaje», en El personaje novelesco, Marina Mayoral (coord.), Madrid, Cátedra, págs. 13-18.

FANON, Frantz (1976), Sociología de una revolución, México, Ediciones Era.

FERnÁndez-Cubas, Cristina (2009), El vendedor de sombras, Barcelona, Ediciones Alfabia.

Flavio, Regina (1938?), Alma de Marruecos, Barcelona-Sevilla, Ediciones Betis.

Gómez García, Luz (2009), Diccionario de islam e islamismo, Madrid, Espasa Libros.

IBÁÑ̃z Blanco, Blanca (1956), Noche nupcial sin novia, Granada, Imprenta José María Ventura Hita.

Jadraque, María Teresa de (1954), Halima, Madrid-Cádiz, Editorial Escelicer.

- (1954), Halima, Madrid, Editorial Escélicer.

Kunz, Marco (2002), «La Polonia de Getafe: Algún día, cuando pueda llevarte a Varsovia, de Lorenzo Silva», en Irene Andrés Suárez, Marco Kuntz e Inés D'Ors (eds.), La inmigración en la literatura española contemporánea, Madrid, Verbum, págs. 165-214.

Linares BeCerra, Concha (1962), Cita en el paraíso, Madrid, C.L.B Sáez.

- (1971), Muchachas sin besos, Madrid, Editorial Cunillera.

López Sarasúa, Concha (1988), A vuelo de pájaro sobre Marruecos, Alicante, Editorial Cálamo.

- (2000), La llamada del almuédano, Alicante, Editorial Cálamo.

- (2002), ¿Qué buscabais en Marrakech?, Alicante, Editorial Cálamo.

Marín, Manuela (2015), Testigos coloniales: españoles en Marruecos, Barcelona, Bellaterra.

Martel, Carmen (1956), ¡Demasiado tarde!, Madrid, Editorial Pueyo.

Martin De La Escalera, Carmen (1945), Fatma. Cuentos de mujeres marroquíes, Madrid, Publicaciones África. Instituto de Estudios Políticos. 
Martín-Márquez, Susan (2011), Desorientaciones. El colonialismo español en África y la performance de identidad, Barcelona, Bellaterra.

Mateo Dieste, José Luis (2005), «Amores prohibidos. Fronteras sexuales y uniones mixtas en el Marruecos colonial», en Ana Isabel Planet Contreras y Fernando Ramos López (coords.), Relaciones hispano-marroquies: una vecindad en construcción, Madrid, Ediciones del Oriente y del Mediterráneo, págs. 128-159.

Nonell, Carmen (1956), Zoco grande, Madrid, Editorial Colenda.

RIVAs, Josefina (1949), Noches de Tánger, Barcelona, Bruguera.

RORTY, Richard (2000), Verdad y progreso. Escritos filosóficos, Barcelona, Paidós.

SAID, Edward W. (1985), «Orientalism reconsidered» in Cultural Critique, no 1, Autumn, págs. 89-107.

- (2003), Orientalismo, Barcelona, Debolsillo.

- (2012), Cultura e imperialismo, Barcelona, Anagrama.

SPIVAK, Gayatri Ch. (2003), «¿Puede hablar lo subalterno?» en Revista Colombiana de Antropología, Vol. 39, enero-diciembre, págs. 297-364.

- (2010), Crítica de la razón poscolonial. Hacia una historia del presente evanescente, Madrid, Akal.

- (2013), En otras palabras, en otros mundos. Ensayos sobre política cultural, Argentina, Paidós.

Pcci (2016), Informe anual. Islamofobia en España 2015, Plataforma Ciudadana contra la Islamofobia.

Villardefrancos, Marisa (1953), El sol nace de madrugada, Madrid, Biblioteca de Chicas.

- (1956), Alma, Madrid, Biblioteca de Chicas.

ViÑuelas, María (1956), Los vencidos, Madrid, Aguilar. 